\title{
Erratum to: How the vestibular system modulates tactile perception in normal subjects: a behavioural and physiological study
}

\author{
Elisa Raffaella Ferrè • Anna Sedda • \\ Martina Gandola $\cdot$ Gabriella Bottini
}

Published online: 15 February 2011

(C) Springer-Verlag 2011

\section{Erratum to: Exp Brain Res (2011) 208:29-38 \\ DOI 10.1007/s00221-010-2450-9}

In the original publication of this article, the following sentence on p. 29 should have read: 'Caloric vestibular stimulation (CVS) is a physiological technique demonstrated to transiently improve hemianaesthesia in right brain-damaged patients (Vallar et al. in Cortex 26(1):123-31, 1990; Vallar et al. in Brain 116:71-86, 1993; Bottini et al. in Nature 376:778-781, 1995)' instead of 'right brain-damaged patients (Bottini et al. in Exp Brain Res 99(1):164-169, 1994, Nature 376:778-781, 1995, Neurology 65(8):1278$1283,2005)$ ' as given.

Moreover, on p. 35, the sentence should be read: 'Moreover, CVS with cold water in the left ear can transiently improve hemianaesthesia in right brain-damaged

The online version of the original article can be found under doi:10.1007/s00221-010-2450-9.

E. R. Ferrè · A. Sedda · G. Bottini ( $\square)$

Department of Psychology, University of Pavia,

Piazza Botta 6, 27100 Pavia, Italy

e-mail: gbottini@unipv.it

E. R. Ferrè

e-mail: elisa.ferre@unipv.it

A. Sedda

e-mail: sedda.anna@gmail.com

M. Gandola

Department of Psychology,

University of Milano Bicocca, Milan, Italy

e-mail: martina.gandola@unimib.it

G. Bottini

Cognitive Neuropsychology Laboratory,

Niguarda Ca' Granda Hospital, Milan, Italy patients (Vallar et al., 1990, 1993; Bottini et al. 1995)' instead of "patients (Bottini et al. 1994, 1995, 2001).

In addition, the citation on p. 30 and p. 35 should be 'Been et al. 2007'.

Finally, the following references should have read as follows:

\section{References}

Bottini G, Paulesu E, Sterzi R, Warburton E, Wise RJ, Vallar G, Frackowiak RS, Frith CD (1995) Modulation of conscious experience by peripheral sensory stimuli. Nature 376:778-781

Bottini G, Paulesu E, Frith CD, Frackowiak RS (1996) Functional anatomy of the human vestibular cortex. In: Collard M, Jeannerod M, Christen Y (eds) Le cortex vestibulaire. Editions Irvinn, Paris, pp 27-48

Grüsser OJ, Pause M, Schreiter U (1990) Localization and responses of neurones in the parieto-insular vestibular cortex of awake monkeys (Macaca fascicularis). J Physiol 430:537-557

Johansson RS, Vallbo AB, Westling G (1980) Thresholds of mechanosensitive afferents in the human hand as measured with von Frey hairs. Brain Res 184:343-351

Wolff BB (1984) Methods of testing pain mechanisms in normal man. In: Wall PD, Melzack R (eds). Textbook of pain. Churchill Livingstone, Edinburgh, pp 186-194 